\title{
PENGARUH STRUKTUR KEPEMILIKAN DAN UKURAN KANTOR AKUNTAN PUBLIK TERHADAP TINGKAT KEPATUHAN PENGUNGKAPAN TRANSAKSI BERELASI BERDASARKAN PSAK NO 7 TENTANG PENGUNGKAPAN PIHAK-PIHAK BERELASI
}

\author{
Vania Nur Annisa Harijanto \\ Prodi Akuntansi Universitas Negeri Yogyakarta \\ vania.harijanto22@gmail.com
}

\begin{abstract}
Abstrak : Pengaruh Struktur Kepemilikan Dan Ukuran Kantor Akuntan Publik Terhadap Tingkat Kepatuhan Pengungkapan Transaksi Berelasi Berdasarkan Psak No 7 Tentang Pengungkapan Pihak-Pihak Berelasi. Penelitian ini bertujuan untuk menganalisis pengaruh struktur kepemilikan dan ukuran kantor akuntan publik (KAP) terhadap tingkat kepatuhan pengungkapan transaksi berelasi pihak berdasarkan PSAK No 7 tentang pengungkapan pihak-pihak berelasi. Penelitian ini menggunakan pendekatan kuantitatif. Jumlah sampel dalam penelitian sebanyak 52 perusahaan yang bergerak dalam sektor utama dan terdaftar di Bursa Efek Indonesia (BEI). Data yang digunakan dalam penelitian ini berupa laporan keuangan yang didapatkan dari website BEI. Uji asumsi klasik meliputi uji normalitas, uji multikolinearitas, dan uji heteroskesdastisitas. Uji hipotesis yang digunakan adalah analisis regresi linear berganda. Hasil dari penelitian ini adalah : (1) struktur kepemilikan tidak berpengaruh signifikan terhadap tingkat kepatuhan pengungkapan transaksi pihak berelasi, (2) ukuran KAP berpengaruh positif dan signifikan terhadap tingkat kepatuhan pengungkapan transaksi pihak berelasi.
\end{abstract}

Kata kunci: Struktur Kepemilikan, Ukuran Kantor Akuntan Publik, Tingkat Kepatuhan Pengungkapan Transaksi Berelasi

Abstract : The Effect Of Ownership Structure And Public Accountant Firm Size On The Level Of Related Party Transactions Disclosure Based On Statement Of Financial Accounting Standard 7 Concerning Disclosure Of Related Parties. This research aims to analyze the influence of ownership structure and public accountant firm size on the level of related party (RPT) transactions disclosure based on statement of Financial Accounting Standard 7 concerning disclosure of related parties. This research used a quantitative method. The number of samples in this research were 52 companies engaged in the main sector and listed on the Indonesia Stock Exchange. The data used in the form of financial statements obtained from Indonesia Stock Exchange's website. Classic assumption test included normality test, multicolinearity test, and heteroscedasticity test. Hypothesis test used was multiple regression analysis. The results of this study are: (1) ownership structure have no significant effect on the level of RPT disclosure, (2) public accounting firm size significant and positively affect the level of RPT disclosure.

Keywords: ownership structure, public accounting firm size, related party transaction disclosure level

PENDAHULUAN

Perusahaan yang merupakan salah

satu entitas ekonomi tentunya

membutuhkan dana untuk melakukan

ekspansi perusahaan. Perusahaan akan

melakukan go public agar dapat

mendapatkan tambahan dana melalui

investasi. Go public atau sering disebut juga penawaran umum adalah kegiatan penawaran saham yang dilakukan oleh perusahaan kepada masyarakat (publik). Perusahaan tersebut akan tercatat di bursa menjadi perusahaan publik atau terbuka jika menawarkan saham kepada publik. Perusahaan-perusahaan yang telah go public dan telah tercatat dalam Bursa Efek 


\section{JURNAL NOMINAL / VOLUME VIII NOMOR 1 / TAHUN 2019}

Indonesia (BEI) tersebut terbagi dalam sembilan sektor menurut Jakarta Stock Exchange Industrial Classification (JASICA). Sektor-sektor tersebut meliputi sektor pertanian; pertambangan; industri dasar dan kimia; aneka industri; industri barang konsumsi; properti, real estate dan konstruksi bangunan; infrastruktur, utilitas, dan transportasi; keuangan; dan perdagangan, jasa dan investasi. Kepemilikan dari masing-masing perusahaan pun berbeda-beda.

Report on the Observance of Standard and Codes (ROSC) menemukan bahwa terdapat lima kategori kepemilikan di Indonesia, yaitu kepemilikan oleh keluarga dan grup, kepemilikan oleh negara (BUMN), kepemilikan bank, kepemilikan asing, dan kepemilikan secara independen bukan bagian dari grup. Price Waterhouse Cooper $(\mathrm{PwC})$, sebuah perusahaan audit asal Amerika Serikat melakukan survei tentang bisnis keluarga di Indonesia. Hasilnya, lebih dari 95 persen perusahaan di Indonesia merupakan bisnis keluarga.

Kepemilikan keluarga, seperti pada penelitian Muslimin (2009), menggunakan kriteria untuk menentukan perusahaan keluarga seperti yang digunakan oleh Andres (2006), yaitu minimal 50 persen dari total saham dimiliki oleh keluarga tertentu, atau jika kurang dari 50 persen terdapat anggota keluarga yang mempunyai jabatan pada Dewan Direksi atau Dewan
Komisaris perusahaan. Presentase yang sebelumnya 25 persen pada Andres (2006) diubah menjadi 50 persen. Pemilihan angka 50 persen tersebut sesuai dengan peraturan Bursa Efek Indonesia, bahwa pemegang saham perusahaan dengan jumlah 50 persen atau lebih harus dilaporkan ke bursa, sehingga pengelompokan antara perusahaan keluarga dan non keluarga dapat dilakukan dengan lebih mudah.

Di Indonesia, kepemilikan keluarga dan grup mendorong terjadinya transaksi pihak berelasi. Transaksi pihak berelasi adalah suatu pengalihan sumber daya, jasa atau kewajiban antara etitas pelapor dengan pihak-pihak berelasi, terlepas apakah ada harga yang dibebankan (PSAK No. 7 Tahun 2015). Sari (2014:3) menyebutkan bahwa perusahaan memiliki tiga motivasi mengapa mereka melakukan transaksi pihak berelasi ini. Pertama, digunakan untuk meminimalkan biaya transaksi (Cook, 1977 dan Fishman dan Khanna, 1998). Kedua, digunakan untuk memanipulasi laba (Jian dan Wong, 2003; Aharony et al., 2009). Ketiga, untuk tujuan tunneling (Cheung et al., 2009a; Cheung et al., 2009b; Cheung et al., 2006). Motivasi kedua dan ketiga tersebut merupakan motivasi oportunis, atau motivasi yang mementingkan diri sendiri.

Terkait dengan motivasi ketiga, yaitu tujuan tunneling, yang merupakan motivasi oportunis, transaksi pihak berelasi 


\section{JURNAL NOMINAL / VOLUME VIII NOMOR 1 / TAHUN 2019}

dapat digunakan sebagai tunnel untuk mentransfer sumber daya keluar perusahaan, untuk kepentingan pemegang saham pengendali dengan mengorbankan kepentingan pemegang saham nonpengendali. Hal tersebut merugikan salah satu pihak dan mendorong terjadinya konflik kepentingan di perusahaan, yang merupakan masalah keagenan. Konflik ini pulalah yang merupakan karakteristik dari kepemilikan grup.

Permasalahan tunneling tersebut sulit terdeteksi karena penegakan hukum yang rendah, sistem corporate governance yang buruk, dan disclosure yang rendah. Kaitannya dengan penegakan hukum di Indonesia, perangkat hukum di Indonesia telah berusaha untuk melindungi pemegang saham minoritas. Perlindungan tersebut dilakukan dengan adanya Undang-Undang Perseroan Terbatas (UU PT) tahun 2007, Undang-Undang Pasar Modal (UU PM), dan Peraturan Bapepam-LK. Permasalahan yang akhirnya timbul adalah upaya yang harus dilakukan untuk menempuh jalur hukum dan kepedulian pemegang saham minoritas itu sendiri terhadap akivitas yang dilakukan oleh perusahaan, karena pemegang saham hanya mementingkan keuntungan jangka pendek dari aktivitas trading yang mereka lakukan. Terkait dengan rendahnya disclosure, masyarakat akan sulit menilai apakah perusahaan melakukan transaksi pihak berelasi untuk tujuan ekonomi atau untuk tujuan oportunis. Pengguna laporan keuangan pun juga akan sulit untuk menentukan keputusan.

Rendahnya disclosure yang dilakukan oleh perusahaan terkait pengungkapan transaksi berelasi membuat adanya peran auditor yang independen, kompeten, dan berkualitas, yang dapat memberikan jaminan eksternal dan objektif kepada anggota dewan dan pemegang saham bahwa laporan keuangan menunjukkan posisi keuangan dan kinerja perusahaan yang dapat dipercaya sangatlah penting. Dalam banyak kasus, transaksi pihak berelasi ini tidak diungkapkan secara eksplisit. Jadi, auditor harus dapat memeriksa secara rinci atas transaksi tersebut. Peran auditor berkualitas yang dapat memastikan bahwa perusahaan mengungkapkan transaksi pihak berelasi yang ada dalam perusahaan mereka sangat dibutuhkan. Perusahaan akan mencari kantor akuntan publik (KAP) yang kredibilitasnya tinggi untuk meningkatkan kredibilitas laporan keuangan dimata pemakai laporan keuangan (Halim, 1997 dalam Tida, 2011). KAP yang lebih besar (Big 4) dianggap sebagai penyedia jasa audit yang lebih mampu mempertahankan independensi daripada KAP yang lebih kecil.

Struktur kepemilikan dalam perusahaan juga dapat mempengaruhi 


\section{JURNAL NOMINAL / VOLUME VIII NOMOR 1 / TAHUN 2019}

disclosure. Terdapat dua bentuk umum struktur kepemilikan perusahaan di Indonesia dan Asia, yaitu struktur kepemilikan tersebar dan terkonsentrasi. Pada struktur kepemilikan tersebar, pemegang saham tidak bisa mengendalikan tindakan manajemen, sedangkan pada struktur kepemilikan terkonsentrasi, pemegang saham dapat mengendalikan tindakan manajemen, atau bahkan menjadi bagian dari manajemen tersebut. Perbedaan dari kedua struktur tersebut adalah proses pengambilan keputusannya. Pemegang saham mayoritas memiliki insentif untuk melakukan ekspropriasi terhadap pemegang saham minoritas berkaitan dengan hal tersebut. Pemegang saham mayoritas memiliki kemampuan untuk memengaruhi proses pelaporan keuangan. Kemampuan tersebut dapat membuat pemegang saham mayoritas perusahaan dengan konsentrasi kepemilikan dapat memengaruhi kualitas laporan keuangan (Silviana, 2012).

Terkait dengan disclosure, khususnya terkait pengungkapan transaksi pihak berelasi, pada PSAK No. 7 sendiri disebutkan mengenai pengungkapan pihakpihak berelasi. Pernyataan ini bertujuan untuk memastikan bahwa laporan keuangan entitas berisi pengungkapan yang diperlukan untuk dijadikan perhatian terhadap kemungkinan bahwa posisi keuangan dan laba rugi telah dipengaruhi oleh keberadaan pihak-pihak berelasi dan oleh transaksi dan saldo, termasuk komitmen, dengan pihak-pihak tersebut. Adanya pengungkapan transaksi berelasi yang diatur dalam PSAK No. 7 tersebut, diharapkan dapat membuat perusahaan melaporkan transaksi berelasi yang ada di perusahaannya dalam laporan keuangan perusahaan dengan rinci, supaya memudahkan pengguna laporan keuangan dalam menilai transaksi berelasi tersebut.

\section{METODE PENELITIAN}

\section{Jenis Penelitian}

Penelitian ini menggunakan pendekatan kuantitatif dengan metode penelitian kausal-komparatif, yaitu mengidentifikasi pengaruh antara variabel satu terhadap variabel lainnya (Widarto, 2013)

\section{Waktu Penelitian}

Penelitian ini dilakukan dengan menggunakan data sekunder yang diperoleh dari laporan tahunan perusahaan listing BEI tahun 2016, yang diperoleh dari http://ww.idx.co.id dan sumber lain yang relevan. Kemudian, penelitian ini dilakukan mulai bulan Desember tahun 2017 hingga Juli 2018.

\section{Populasi dan Sampel Penelitian}

Populasi dalam penelitian ini adalah perusahaan-perusahaan sektor utama yang terdaftar di Bursa Efek Indonesia pada tahun 2016. Pengambilan sampel dilakukan 
JURNAL NOMINAL / VOLUME VIII NOMOR 1 / TAHUN 2019

dengan metode purposive sampling, dengan kriteria:

a) Perusahaan yang dijadikan sampel penelitian adalah perusahaan yang listed di BEI selama tahun 2016.

b) Perusahaan termasuk dalam perusahaan sektur utama yakni perusahaan sektor pertambangan dan sektor pertanian dikarenakan kedua sektor tersebut merupakan sektor penghasil bahan baku yang dinilai memiliki kemungkinan lebih tinggi terjadinya transaksi berelasi dengan tujuan oportunis.

c) Perusahaan telah mempublikasikan laporan keuangan perusahaan yang telah diaudit.

d) Merupakan perusahaan non BUMN. Hal tersebut diatur dalam PSAK No 07 Tahun 2015 Paragraf 28, karena terdapat perbedaan peraturan pengungkapan antara perusahaan BUMN dan non BUMN.

e) Memiliki informasi tentang pengungkapan transaksi pihak berelasi (Related Party Transaction).

\begin{tabular}{lr}
\hline \multicolumn{1}{c}{ Kriteria Sampel } & $\mathrm{N}$ \\
\hline Perusahaan Sektor Utama & 59 \\
Tidak melaporkan Laporan & $(6)$ \\
Keuangan & \\
Tidak memiliki pihak berelasi/ & $(1)$ \\
pihak berelasi dengan & \\
pemerintah & \\
Jumlah sampel yang digunakan & 52 \\
\hline
\end{tabular}

Tabel 1. Sampel Penelitian

\section{Definisi Operasional Variabel}

a) Tingkat Kepatuhan Pengungkapan Transaksi Berelasi (Y)

Pengungkapan pihak-pihak berelasi memastikan bahwa laporan keuangan entitas berisi pengungkapan yang diperlukan untuk dijadikan perhatian terhadap kemungkinan bahwa posisi keuangan dan laba rugi telah dipengaruhi oleh keberadaan pihakpihak berelasi dan oleh transaksi dan saldo, termasuk komitmen, dengan pihak-pihak tersebut.

$$
\mathrm{Y}=\frac{\text { nilai pengungkapan }}{\text { total yang diharuskan }} \mathrm{X}
$$

b) Struktur Kepemilikan (X1)

Struktur kepemilikan diukur dengan melihat persentase kepemilikan publik dalam struktur kepemilikan perusahaan (Nugraha, 2010). Kepemilikan Publik menurut Wijayanti (2009) adalah proporsi atau jumlah kepemilian saham yang 


\section{JURNAL NOMINAL / VOLUME VIII NOMOR 1 / TAHUN 2019}

dimiliki oleh publik atau

masyarakat umum yang tidak

memiliki hubungan istimewa

dengan perusahaan.

$\mathrm{X}_{1}=\frac{\text { Total Kepemilikan Saham Publik }}{\text { Jumlah Saham yangBeredar }} \mathrm{X}$

c) Ukuran $\operatorname{KAP}(\mathrm{X} 2)$

Ukuran KAP dilihat dari besar kecilnya KAP yang mengaudit perusahaan. Untuk membedakan ukuran besar kecilnya $\mathrm{KAP}$, dilihat dari hubungan afiliasi yang dimiliki oleh KAP. Pengukuran menggunakan variabel dummy, yaitu dengan memberikan angka 1 untuk KAP yang berafiliasi dengan Big 4 dan 0 sebaliknya (Fodio, dkk. 2015).

\section{KAP Big $4=1$} KAP non Big $4=0$

KAP Big 4 yang berafiliasi dengan auditor di Indonesia, yang terdiri dari:

1) Ernst \& Young (EY) yang berafiliasi dengan Prasetio, Sarwoko \& Sandjaja; Purwantono, Sarwoko \& Sandjaja.

2) Klynveld Peat Marwick Goerdeler (KPMG) yang berafiliasi dengan Sidharta Sidharta \& Widjaja.

3) Deloitte Touche Tohmatsu (Deloitte) yang berafiliasi dengan Hans Tuanakotta Mustofa \& Halim;
Osman Ramli Satrio \& Rekan; Osman Bing Satrio \& Rekan.

4) Price Waterhouse Cooper $(\mathrm{PwC})$ yang berafiliasi dengan Haryanto Sahari \& Rekan; Tanudiredja, Wibisena \& Rekan.

Data, Intrumen, dan Teknik Pengumpulan

Data

Data yang digunakan berupa laporan keuangan yang didapatkan dari http://ww.idx.co.id dan sumber lain yang relevan.

\section{Teknik Analisis Data}

Teknik analisis data menggunakan analisis statistik deskriptif, pengujian asumsi klasik, dan pengujian hipotesis. Pengujian asumsi klasik terdiri dari uji normalitas, uji multikolinearitas, dan uji heteroskedastisitas. Uji hipotesis terdiri dari analisis regresi linear berganda. 
JURNAL NOMINAL / VOLUME VIII NOMOR 1 / TAHUN 2019

HASIL

PENELITIAN

DAN

PEMBAHASAN

Analisis Statistik Deskriptif

Tabel 2. Statistik Deskriptif

\begin{tabular}{lrrrrl}
\hline Var. & N & Min & Max & Mean & $\begin{array}{l}\text { Std. } \\
\text { dev. }\end{array}$ \\
\hline TPB & 52 & 0 & 0,857 & 0,500 & 0,207 \\
\hline SK & 52 & 2,47 & 86,84 & 30,15 & 19,94 \\
\hline UKAP & 52 & 0 & 1 & 0,42 & 0,499 \\
\hline
\end{tabular}

Tabel 2. Statistik Deskriptif (Sumber data

diolah 2018)

Berdasarkan tabel 2, tingkat kepatuhan pengungkapan transaksi berelasasi (TPB) memiliki nilai terendah 0 , yang dimiliki oleh PT Inti Agri Resources Tbk. dan PT Perdana Karya Perkasa Tbk. Kedua perusahaan tersebut memiliki pihak berelasi, namun didalam laporan keuangannya tidak dijelaskan lebih lanjut terkait transaksi berelasi perusahaan. Nilai tertinggi pengungkapan sebesar 0,857 dan nilai rata-rata kepatuhan pengungkapan sebesar 0,500 menunjukkan rata-rata tingkat kepatuhan pengungkapan transaksi berelasi berada pada angka $50 \%$.

Struktur Kepemilikan memiliki nilai terendah 2,47 yang berarti kepemilikan publik paling rendah sebesar 2,47\%, yaitu pada Toba Bara Sejahtera Tbk. Nilai tertinggi sebesar 86,84 yang berarti kepemilikan publik paling tinggi sebesar 2,47\% dimiliki oleh Inti Agri Resource Tbk. Rata-rata struktur kepemilikan berada pada angka 30,15\%.
Ukuran Kantor Akuntan Publik (KAP) menggunakan variabel dummy. Angka 1 yang menunjukkan bahwa perusahaan tersebut menggunakan KAP yang berafiliasi dengan Big 4, sementara angka 0 menunjukkan bahwa perusahaan tersebut menggunakan KAP yang tidak berafiliasi dengan Big 4 . Jumlah perusahaan yang diaudit oleh KAP terafiliasi Big 4 sebanyak dua pulu dua perusahaan, sedangkan tigah puluh perusahaan yang lain diaudit oleh KAP yang tidak berafiliasi dengan Big 4. Nilai rata-rata ukuran KAP sebesar 0,42.

\section{Pengujian Asumsi Klasik}

\section{1) Uji Normalitas}

\begin{tabular}{lll}
\hline \multicolumn{1}{c}{ Variabel } & Signifikansi & Keterangan \\
\hline $\begin{array}{l}\text { Data } \\
\text { Residual }\end{array}$ & 0,200 & Normal \\
\hline Tabel 3. Hasil Uji Normalitas (Sumber: Data \\
\multicolumn{3}{c}{ diolah, 2018) }
\end{tabular}

Berdasarkan hasil uji normalitas pada tabel 3, dapat dilihat bahwa nilai signifikansi Kolmogorov-Smirnov adalah 0,200. Nilai tersebut lebih besar dari 0,05. Dengan demikian, dapat disimpulkan bahwa data dalam penelitian ini berdistribusi normal. 
JURNAL NOMINAL / VOLUME VIII NOMOR 1 / TAHUN 2019

\section{2) Uji Multikolinearitas}

Tabel 4. Hasil Uji Multikolinearitas

\begin{tabular}{lcc}
\hline \multicolumn{1}{c}{ Variabel } & Tolerance & Nilai VIF \\
\hline SK & 0,923 & 1,085 \\
\hline UKAP & 0,922 & 1,085
\end{tabular}

Tabel 4. Hasil Uji Multikolinearitas (Sumber: Data diolah, 2018)

Berdasarkan hasil uji multikolinearitas pada tabel 4, dapat diketahui bahwa Nilai Tolerance dari semua variabel independen adalah lebih besar dari 0,10 dan nilai VIF kurang dari 10. Dengan demikian, dapat disimpulkan bahwa model regresi yang digunakan dalam penelitian ini tidak memiliki masalah multikolinearitas.

\section{3) Uji Heteroskesdastisitas}

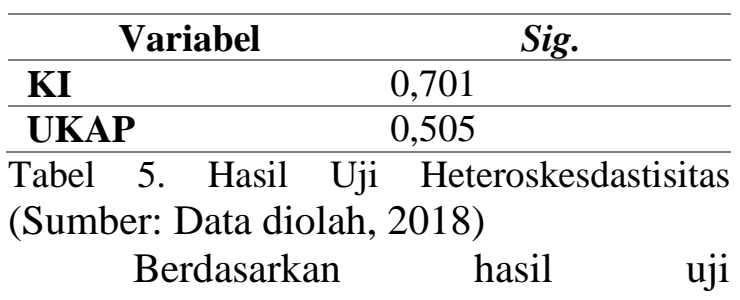

heteroskesdastisitas pada tabel 5, dapat diketahui bahwa parameter koefisien untuk semua variabel independen memiliki nilai signifikansi di atas 0,05. Hal ini menunjukkan bahwa model regresi tidak memiliki masalah heteroskedastisitas.

\section{Pengujian Hipotesis}

Hasil analisis regresi linear berganda dengan menggunakan perangkat lunak pengolah data dapat dilihat pada tabel di bawah ini.

\begin{tabular}{lrrr}
\hline \multicolumn{1}{c}{ Variabel } & $\begin{array}{c}\text { Koefisien } \\
\text { Regresi }\end{array}$ & Sig. t & Alpha \\
\hline Konstanta & 0,479 & - & - \\
\hline $\begin{array}{l}\text { Struktur } \\
\text { Kepemilikan }\end{array}$ & $-0,001$ & 0,612 & 0,05 \\
\hline Ukuran KAP & 0,104 & 0,085 & 0,10 \\
\hline $\boldsymbol{r}$ square & 0,078 & & \\
\hline Sig. F & 0,135 & & \\
\hline
\end{tabular}

Tabel 6. Hasil Uji Hipotesis (Sumber: Data diolah, 2018)

Pada tabel 6, terliht bahwa masing masing variabel penelitian yang digunakan telah memiliki koefisien regresi yang dapat dibuat kedalam sebuah model regresi berganda seperti terlihat dibawah ini:

$$
Y=0,479-0,001 X_{1}+0,104 X_{2}
$$

Sesuai dengan hasil pengujian, terlihat nilai koefisien determinasi $\left(\mathrm{R}^{2}\right)$ sebesar 0,078. Hasil yang diperoleh tersebut menunjukan bahwa variabel struktur kepemilikan dan ukuran KAP mampu memberikan kontribusi sebesar 0,078 atau $7.8 \%$ sedangkan sisanya sebesar 92,2\% lagi dipengaruhi oleh variabel lain yang tidak digunakan didalam penelitian ini.

Pada model analisis juga diperoleh nilai F-sig sebesar 0,135. Pada tahapan pengujian statistik, digunakan tingkat kesalahan sebesar 0,05. Hasil yang diperoleh tersebut menunjukan bahwa nilai signifikan sebesar 0,135 lebih besar dari 0,05. Dapat disimpulkan bahwa struktur kepemilikan dan ukuran KAP merupakan variabel yang kurang kuat untuk dijadikan prediktor tingkat kepatuhan pengungkapan transaksi pihak berelasi berdasarkan PSAK 


\section{JURNAL NOMINAL / VOLUME VIII NOMOR 1 / TAHUN 2019}

No 7 tentang pengungkapan pihak-pihak berelasi.

1) Pengujian Hipotesis Pertama

Hipotesis pertama dalam penelitian ini adalah struktur kepemilikan berpengaruh positif terhadap tingkat kepatuhan pengungkapan transaksi pihak berelasi berdasarkan PSAK No 7 tentang pengungkapan pihak-pihak berelasi.

Berdasarkan hasil uji regresi linear yang telah dilakukan, diperoleh hasil bahwa variabel memiliki nilai signifikansi t lebih besar dari 0,05 , yaitu sebesar 0,612 , sehingga persamaan garis regresi untuk hipotesis pertama dianggap tidak ada. Seperti yang dikemukakan oleh Azwar (2005), saat hasil analisis menunjukkan tidak signifikan, maka nilai dari variabel terkait diabaikan. Arah model regresi ini adalah negatif. Hal ini dapat dilihat dari koefisien regresi yang bernilai negatif sebesar $-0,001$.

Berdasarkan hasil analisis statistik deskriptif yang telah dilakukan, nilai ratarata kepemilikan saham publik di perusahaan tergolong rendah, yaitu sebesar 30,1542. Kepemilikan saham publik disebuah perusahaan umunya hanya merupakan investor dengan kepemilikan saham dibawah 5\%, atau dapat disebut dengan pemegang saham minoritas, yang mana kurang memiliki kekuatan untuk mendorong manajemen melakukan pengungkapan untuk memenuhi kebutuhan informasinya.

2) Pengujian Hipotesis Kedua

Hipotesis kedua dalam penelitian ini adalah ukuran KAP berpengaruh positif terhadap tingkat kepatuhan pengungkapan transaksi pihak berelasi berdasarkan PSAK No 7 tentang pengungkapan pihak-pihak berelasi.

Berdasarkan Tabel 6, persamaan regresi linear sederhana dalam pengujian hipotesis kedua adalah sebagai berikut.

$$
\mathrm{Y}=0,479+0,104 \mathrm{X}_{2}
$$

Jika variabel ukuran KAP dianggap konstan, maka nilai kepatuhan pengungkapan transaksi pihak berelasi adalah 0,479. Selain itu, dapat dilihat bahwa koefisien regresi memiliki nilai sama dengan 0,104. Hal ini menunjukkan bahwa jika ukuran KAP afiliasi Big 4 bertambah sebesar 1 poin, maka kepatuhan pengungkapan transaksi pihak berelasi akan bertambah sebesar 0,104 dengan asumsi bahwa faktor-faktor lain dianggap konstan.

Arah model regresi ini adalah positif, dilihat dari koefisien regresi yang bernilai positif sebesar 0,104 . Koefisien determinasi (r square) memiliki nilai sebesar 0,078 yang berarti variabel ukuran KAP memiliki pengaruh sebesar 7,8\% terhadap tingkat kepatuhan pengungkapan transaksi berelasi. 


\section{JURNAL NOMINAL / VOLUME VIII NOMOR 1 / TAHUN 2019}

Nilai sigifikansi t sebesar 0,085 , dimana angka signifikansi tersebut lebih kecil dari 0,10. Pada variabel ukuran KAP yang menggunakan variabel dummy, signifikansi dianggap memiliki pengaruh signifikan terhadap variabel dependen apabila nilai signifikansi lebih kecil dari 0,10 (Juvita dan Siregar, 2013). Karena signifikansi dalam penelitian ini lebih kecil dari 0,10, maka hipotesis "ukuran KAP berpengaruh positif terhadap tingkat kepatuhan pengungkapan transaksi pihak berelasi" didukung.

Hasil pengujian ini sesuai dengan teori yang menyatakan bahwa semakin besar ukuran KAP, maka integritas laporan keuangan perusahaan yang diaudit juga semakin tinggi. Hal ini dikarenakan KAP yang besar memiliki insentif yang lebih untuk menghindari hal-hal yang dapat merusak reputasinya dibandingkan dengan KAP yang lebih kecil (DeAngelo, 1981 dalam Astria, 2011).

\section{SIMPULAN DAN SARAN}

\section{Simpulan}

1) Struktur Kepemilikan tidak berpengaruh terhadap tingkat kepatuhan pengungkapan transaksi berelasi berdasarkan PSAK 7 .

2) Ukuran Kantor Akuntan Publik (KAP) berpengaruh positif terhadap tingkat kepatuhan pengungkapan transaksi berelasi berdasarkan PSAK 7.

3) Struktur Kepemilikan dan ukuran KAP secara bersama-sama tidak berpengaruh terhadap tingkat kepatuhan pengungkapan transaksi berelasi berdasarkan PSAK 7.

\section{Saran}

1) Bagi perusahaan

Perusahaan harus dapat mematuhi aturan mengenai transaksi berelasi dan melakukan pengawasan apabila di perusahaannya terdapat transaksi pihak berelasi, dalam hal ini terkait pengungkapan transaksi berelasi, agar transparansi kepada pengguna laporan keuangan dan masyarakat dapat tercapai. Selain itu, agar risiko adanya tunneling di perusahaan dapat diantisipasi.

2) Bagi pemegang saham

Pemegang saham harus lebih memahami mengenai transaksi yang ada pada perusahaan, dalam hal ini transaksi pihak berelasi yang terjadi pada perusahaan, supaya dapat ikut mengontrol dengan baik jalannya perusahaan dimana para pemegang saham menanamkan saham mereka, sekalipun kepemilikan sahamnya kecil.

3) Bagi peneliti selanjutnya 


\section{JURNAL NOMINAL / VOLUME VIII NOMOR 1 / TAHUN 2019}

a) Penelitian selanjutnya perlu untuk menambahkan faktor lain sebagai variabel independen, karena masih banyak faktor yang memiliki pengaruh lebih besar terhadap tingkat kepatuhan pengungkapan transaksi berelasi.

b) Objek penelitian perlu diperluas pada sektor-sektor lain yang ada di BEI, sehingga jumlah sampel akan semakin banyak, sehingga penelitian dapat mewakili seluruh sektor perusahaan yang ada di BEI.

\section{DAFTAR PUSTAKA}

Ahmad, Rudy dan Ratna Candra Sari. 2017. Pengaruh Komite Audit, Ukuran Perusahaan, Ukuran KAP terhadap Tingkat Keselarasan Laporan Tahunan dengan Rerangka Integrated Reporting. Jurnal Nominal. Diakses pada 29 Juni 2018.

Apriyani, Hani Werdi. 2015. Pengaruh Corporate Governance dan Karakteristik Perusahaan terhadap Luas Pengungkapan Transaksi Pihak Berelasi di Indonesia. Jurnal Akuntansi Indonesia. (http://jurnal.unissula.ac.id/index.ph p/jai/article/view/876) diakses pada 28 Desember 2017.

Astria, Tia. 2011. Analisis Pengaruh Audit Tenure, Struktur Corporate Governance, dan Ukuran Kap terhadap Integritas Laporan Keuangan. Skripsi. Universitas Diponegoro Semarang. Diakses pada 4 Januari 2018.
Azwar, Saifuddin. 2005. Signifikan Atau Sangat Signifikan?. Jurnal. (https://jurnal.ugm.ac.id/buletinpsiko logi/article/viewFile/13410/9620) diakses pada Juli 2018.

Bursa Efek Indonesia. 2018. Laporan Keuangan dan Tahunan. (http://idx.co.id/perusahaantercatat/laporan-keuangan-dantahunan/) diakses tanggal 25 Februari 2018.

Fodio, M. I., Oba, V. C., Oiukoju, A. B., \& Zik-rullahi, A. A. 2015. IFRS Adoption, Firmm Traits and Audit Timeliness: Evidence from Nigeria. ACTA UNIVERSITAS DANUBIUS Vol. 11, No. 3, 106-119. (http://journals.univ-

danubius.ro/index.php/oeconomica/a rticle/view/2513) diakses pada 28 Desember 2017.

Ghozali, Imam. 2011. Aplikasi Analisis Multivariate dengan Program IBM SPSS 19. Semarang: Universitas Diponegoro.

Heriyanto, Wimbo., Meihendri, dan Muchlizul Hamdi. 2016. Pengaruh Struktur Kepemilikan dan Ukuran Kap terhadap Tingkat Kepatuhan Pengungkapan Wajib Risiko Keuangan: Corporate Governance sebagai Pemoderasi. Jurnal. (http://ejurnal.bunghatta.ac.id/index. php?journal $=$ JFEK\&page $=$ article\&o $\mathrm{p}=$ view\&path $\% 5 \mathrm{~B} \% 5 \mathrm{D}=6522$ ) diakses pada 28 Desember 2017.

Juvita, Desriana dan Sylvia Veronica Siregar. 2013. Pengaruh Corporate Governance terhadap hubungan Besaran dan Pengungkapan Transaksi Pihak Berelasi dengan Manajemen Laba: Studi Empiris Perubahan PSAK No. 7. Jurnal. (https://ejournal.undip.ac.id/index.ph p/akuditi/article/view/12061) diakses pada Juli 2018. 
Kurniawan, Albert. 2014. Metoe Riset untuk Ekonomi \& Bisnis. Bandung: Alfabeta.

Nugraha, Vendi Cahya. 2010. Pengaruh Struktur Kepemilikan dan Ukuran Perusahaan Terhadap Manajemen Laba (Earnings Management) dalam Industri Manufaktur dan Non Manufaktur Periode 2001-2006 di Indonesia. Skripsi. Universitas Sebelas Maret Surakarta. Diakses pada 28 Desember 2017.

Pitasari, Anggita dan Aditya Septiani. 2014. Analisis Pengaruh Struktur Corporate Governance terhadap Tingkat Kepatuhan Pengungkapan Konvergensi IFRS pada Laporan Laba Rugi Komprehensif. Diponegoro Journal of Accounting. (https://ejournal3.undip.ac.id/index.p hp/accounting/article/viewFile/6093/ 5880) diakses pada 28 Desember 2017.

Rofika dan Mustika Debby Apsari. 2011. Faktor yang Mempengaruhi Kelengkapan Pengungkapan Laporan Keuangan pada Perusahaan Manufaktur yang Terdaftar di BEI. Jurnal Sorot. (https://ejournal.unri.ac.id/index.php/ JS/article/view/1994/0) diakses pada Mei 2018.

Santioso, Linda dan Yenny. 2012. FaktorFaktor yang Mempengaruhi Kelengkapan Pengungkapan Wajib dalam Laporan Keuangan pada Perusahaan Manufaktur yang terdaftar di BEI. Jurnal. (http://journal.binus.ac.id/index.php/ winners/article/view/654) diakses pada Mei 2018.

Saham OK. 2018. Sektor Utama BEI. (https://www.sahamok.com/emiten/s ektor-utama-bei/) diakses pada 25 Februari 2018.
Sari, Ratna Candra dan Sugiharto. 2014. Tunneling dan Corporate Governance. Yogyakarta: Gadjah Mada University Press.

Sugiyono. 2011. Metode Penelitian Kuantitatif Kualitatif dan $R \& D$. Bandung: Alfabeta.

Widarto. 2013. Penelitian Ex Post Facto. Yogyakarta: Universitas Negeri Yogyakarta.

Widyawati. 2013. Faktor Faktor yang Mendorong Kelengkapan Pengungkapan Risiko Pada Perusahaan Terbuka di Indonesia. Tesis. Akuntansi Keuangan Universitas Dipenegoro, Semarang. (http://eprints.undip.ac.id/35288/1/Ju rnal_Skripsi.pdf) diakses pada 28 Desember 2017.

Wijayanti, Ngestiana. 2009. Penagruh Profitabilitas, Umur Perusahaan, Ukuran Perusahaan dan Kepemilikan Publik terhadap Ketepatan waktu pelaporan keuangan. Skripsi. Universitas Sebelas Maret Surakarta. Diakses pada 18 Juli 2018. 